\title{
INVESTIGATION OF FACTORS EFFECTING THE MODAL CHOICE AND PUBLIC TRANSPORT USAGE AMONG THE COMMUTERS OF AN EDUCATIONAL INSTITUTE IN LAHORE, PAKISTAN
}

\author{
Khurram Shahid Minhas ${ }^{1}$ \\ ${ }^{1}$ Civil Engineering Department, Imperial College of Business Studies, Lahore, Pakistan
}

Received 3 March 2019; accepted 25 April 2019

\begin{abstract}
The primary aim of this research work is to investigate the factors which affect the modal choice and public transport usage among the commuters in an educational institute of a metropolitan city of Lahore, Pakistan. For this purpose the data was collected from 337 commuters and results were analyzed using Cross Tabulation and ANOVA using IBM SPSS. Results showed that the gender, age group, occupation, monthly income, daily travel distance and presence of driving license among the commuters are the most significant factors which affect their modal choice. Results also showed that the comfort level, ease of access, punctuality and improvement of seating capacity and condition of public buses can encourage the use of public transport among the commuters.
\end{abstract}

Keywords: modal choice, public transport, educational institute.

\section{Introduction}

Lahore has seen a rapid growth in motorization in past couple of years which has produced a lot of traffic problems in the city. Number of motorized vehicles per 1000 residents in Lahore increased from 95 in 2001 to 238 in 2008 (JICA, 2012). Car sales in the city are further expected to grow at the rate of $12 \%$ from 2016 to 2020 (Hussain, 2016). City's transport infrastructure and capacity of roads has not been increased to handle this motorization which has resulted in the poor traffic flow and frequent traffic jams on the roads. City's public transport system also suffers from a lack of attention and it is in very poor shape. This discourages the masses to use the public buses and increases their reliance and preference for other modes of travel like motor bikes and private cars thereby increasing the presence of vehicles on the roads and ultimately resulting in traffic congestion and slower traffic flow in the city. Apart from the daily work commuters, students of colleges and universities are also affected by this poor transport system. Traffic safety situation in the city is also worsening. According to the data shared by City Traffic Police in 2016 almost forty-five thousand crashes took place involving 55\% motorcyclists, bicyclists and pedestrians, $25 \%$ over-speeding and $20 \%$ underage and distracted drivers. Further look into the data showed that almost $20 \%$ of total RTAs in Lahore took place at or near the educational institutes.

${ }^{1}$ Corresponding author: ECFaculty18@imperial.edu.pk 


\section{Literature Review}

Situation of public transport use is also very alarming in Lahore as only $16 \%$ of daily trips are made on public transport as compared with $60 \%$ of Mumbai (JICA, 2012). The introduction of sustainable mass transit system is one of the solutions that reduce traffic congestion and accidents rate. MBS in Public Transport planning is favored in many Asian developing cities because of its lower investment cost and flexible implementation over rail system (Imran, 2009). A great deal of research has gone into investigating planning, performance, and operation of Bus Rapid Transit (BRT); however, relatively less has been done to assess whether its introduction has actually had an appreciable effect on transit use (Jaensirisak \& Klungboonkrong, 2009). In order to cope with the ever increasing traffic congestion in Lahore city, MBS has been introduced in 2013. According to a few academics and professionals a very formal definition for BRTS is: "Bus transit designed as an integrated system of distinct buses and a separate infrastructure with considerable independence from other traffic allowing higher speed, reliability and safety than the Bus Transit System (BTS)” (Robert, 2011). It has dedicated corridor from Northern suburb of Lahore i.e. Shahdara to south-east direction Gajjumatta. According to Punjab Mass Transit Authority, Shahdara station has highest daily ridership of 25,672. The introduction of MBS has reduced travel time and travel cost for passengers. A large amount of people make trips from nearby cities/villages like Rana Town, Sheikhupura, Muridke, Imamia Colony, Kamoki, etc. for work and educational purposes. For developing countries such as Pakistan, road user error is identified as the main cause in at least $70 \%$ of RTAs (Hyder \& Ghaffar, 2006). Road safety literature suggests that increasing percentage of RTAs in Pakistan is due to the violation of traffic rules by the drivers which may be due to unawareness of traffic rules which can affect their perception towards traffic offences. The socio-economic characteristics (income, education, etc.) also influence behavior of drivers towards road traffic violations. A number of studies have shown that men commit more violations and women make more errors. Similarly, for middle-age group, speeding is found to be the most common violation, followed by the failure to stop at traffic signal/signs. For elderly drivers, the most common type of violation is found to be sign-related, followed by turning and precedence transgressions (Iversen \& Rundmo, 2004). Road safety research has also looked into the influences of socio-economic level on attitudes and behavior of drivers towards violations. A study based on Lahore bus drivers' also report a similar trend in which $70 \%$ of the drivers admitted that their attitudes towards driving are significantly influenced by their economic conditions (Jacobs et al., 2000).

\section{Objectives}

Objectives of this research are twofold including:

a. Investigating the factors which effect the modal choice of commuters of an educational institute;

b. Exploring the factors which can encourage the usage of public transport among the commuters of an educational institute. 


\section{Materials and Methods}

\subsection{Study Location}

Imperial College of Business Studies (ICBS) main campus opposite Canal Bank road near Shahkam Industries intersection was taken as a study area for this research. This institute is located near one of the busiest intersection of Lahore namely Shahkam
Industries intersection and suffers from a lot of congestion throughout the day especially at the morning (8-9 AM) and evening peak hour of (4-6 PM). There are a lot of shops, commercial banks, mills, factories and industries located in this area and a significant chunk of heavy vehicles also utilize the intersection throughout the day. The satellite image of the location obtained from Google Maps is presented in Fig. 1.

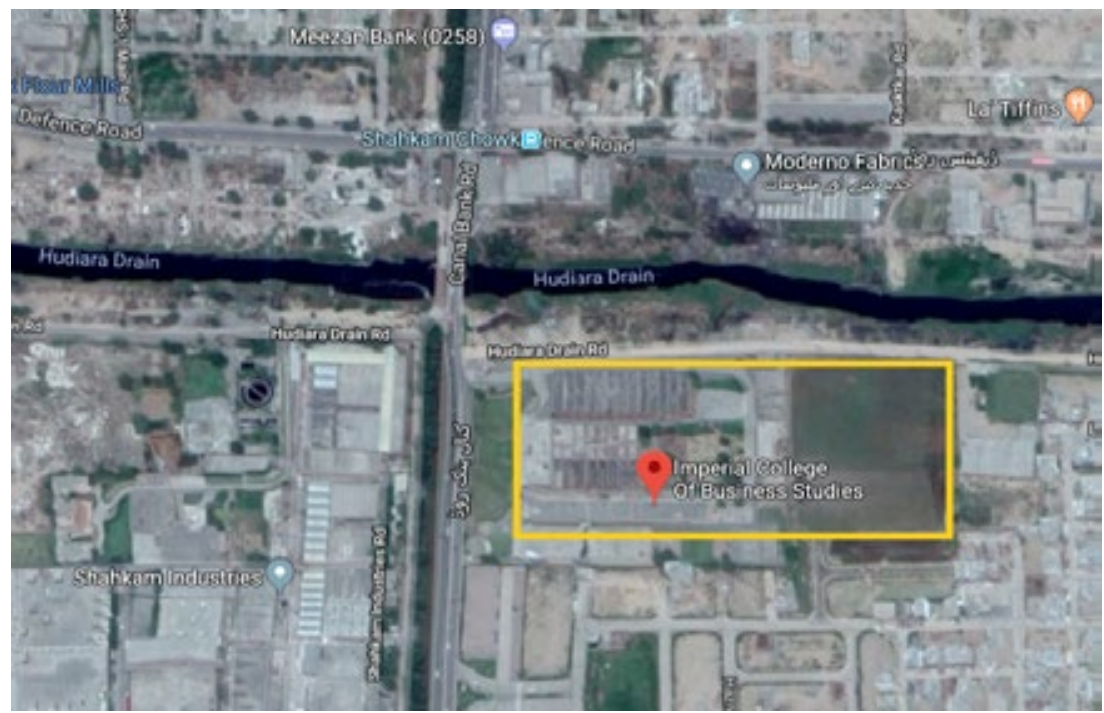

Fig. 1.

Study Location (ICBS Lahore)

\subsection{Sample Size}

The total population of ICBS comprises of about 2,000 people including the college staff, teachers and students. Based on which a sample size of about 337 participants was selected for data collection. Data was collected randomly from these participants through a prepared questionnaire. The Distribution of obtained sample is presented in Fig. 2.

\subsection{Data Collection}

After taking the consent to participate in the study the willing participants were handed the questionnaires and asked to provide information about the following questions:
a. Gender;
b. Age group;
c. Daily travel distance;
d. Occupation; 
e. Monthly income;

f. Family size;

g. Driving license;

h. Current mode of travel;

i. Reason for using the current mode of travel;

j. Factors which can encourage the use of public transport.

\subsection{Data Analysis}

After the data was collected through the filled questionnaires a code book was generated and coding of all the questions was done using IBM SPSS software package. The current mode of travel was treated as a dependent variable while the gender, age group, daily travel distance, occupation, monthly income, family size and driving license were treated as independent variables. Two types of tests were performed on the collected data.

a) Descriptive Statistics

Data was explored and categorized using Cross Tabulation method.

\section{b) Compare Means Test}

One Way Analysis of Variation ANOVA test to assess the statistical significance in the means of the samples based on confidence level of $95 \%$.
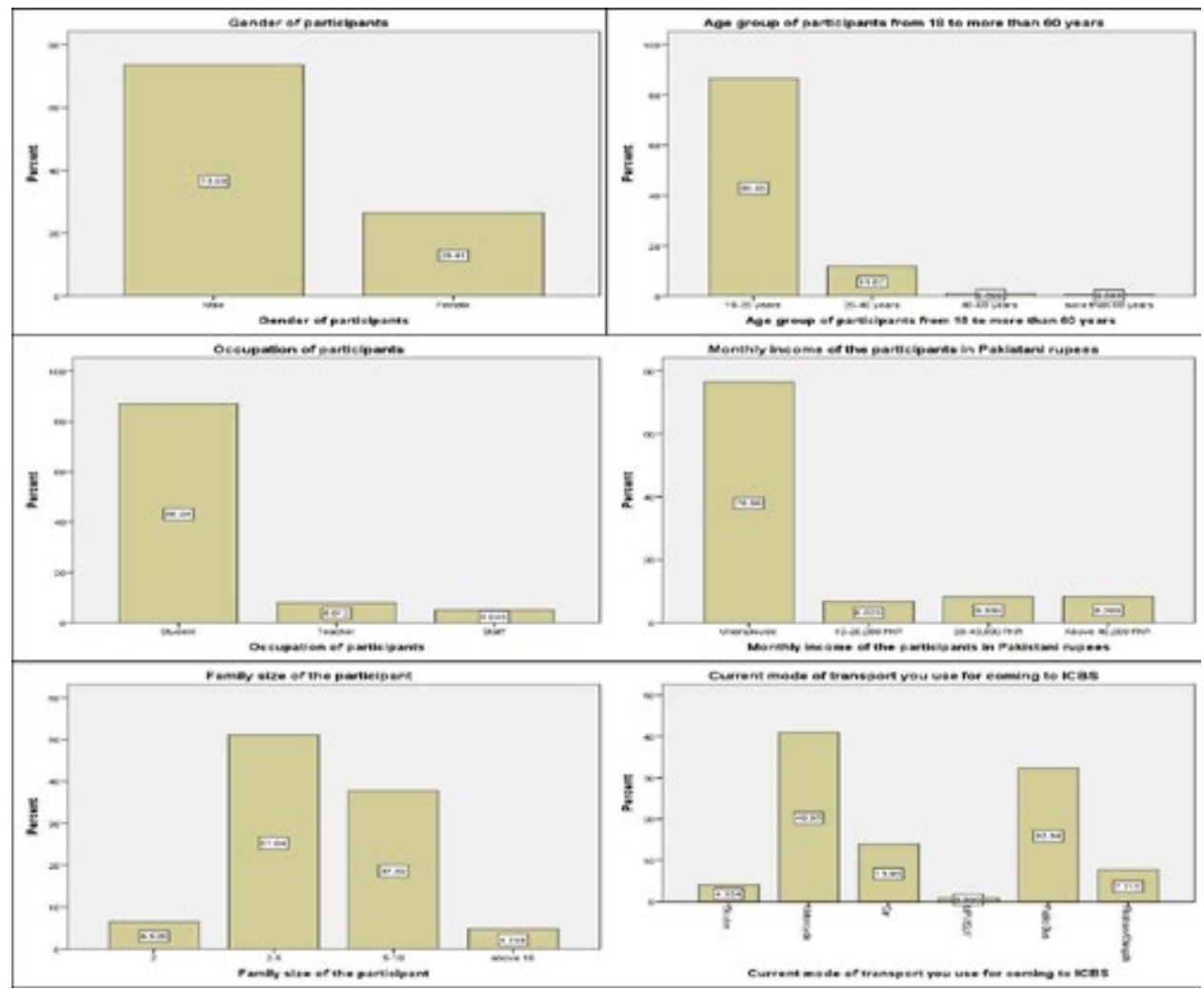

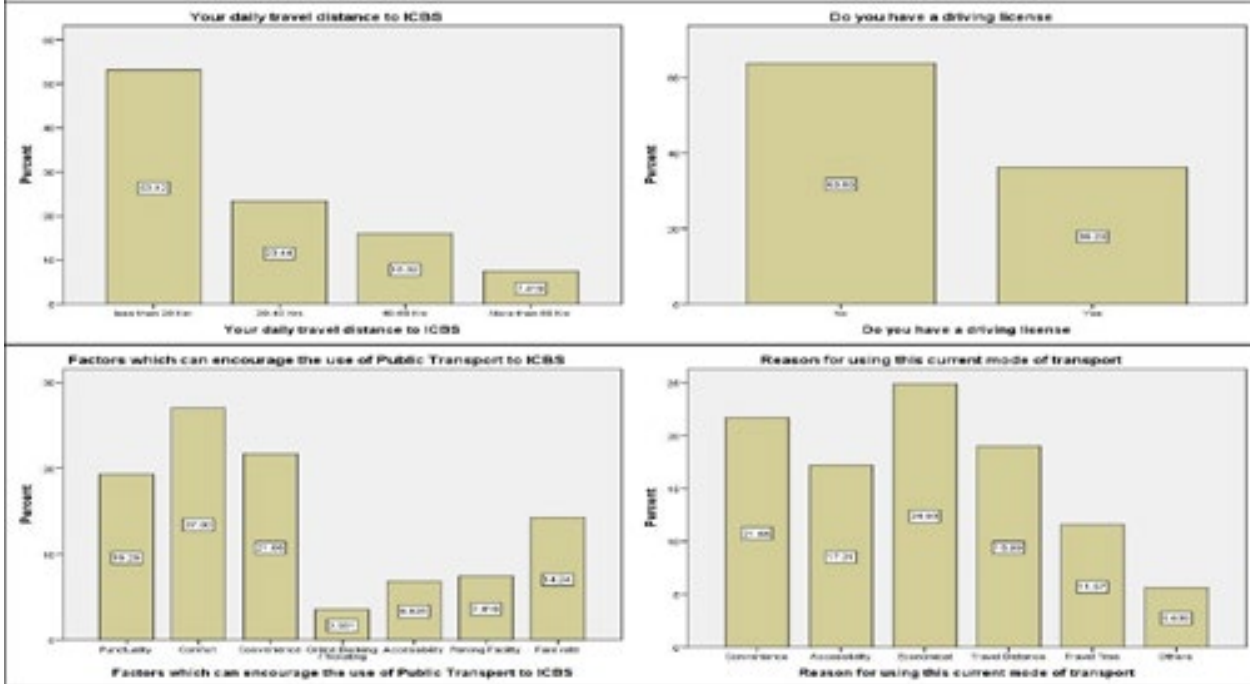

Fig. 2.

Distribution of Sample

\section{Results}

The Cross Tabulation of different categorical variables and their respective Analysis of Variance (ANOVA) test results are presented in this section.

\subsection{Effect of Different Categorical Variables on the Modal Choice of Commuters}

\section{Table 1}

Cross Tab (Modal Choice versus Gender)

\begin{tabular}{|c|c|c|c|c|}
\hline \multicolumn{1}{|c|}{} & Male & Female & Total \\
\hline \multirow{4}{*}{\begin{tabular}{c} 
Current mode of transport you use for $\begin{array}{c}\text { comy } \\
\text { coming to ICBS }\end{array}$ \\
\cline { 2 - 5 }
\end{tabular}} & Bicycle & 12 & 2 & 14 \\
\cline { 2 - 5 } & Motorcycle & 134 & 4 & 138 \\
\cline { 2 - 5 } & Car & 30 & 17 & 47 \\
\cline { 2 - 5 } & MPV/SUV & 2 & 1 & 109 \\
\cline { 2 - 5 } & Public Bus & 13 & 13 & 32 \\
\hline \multicolumn{2}{|c|}{ Total } & 248 & 89 & 337 \\
\hline
\end{tabular}

Results showed that majority of male commuters preferred the use of motorcycles as their mode of travel whereas females were more oriented towards the use of public buses. 
Table 2

ANOVA (Modal Choice versus Gender)

\begin{tabular}{|c|c|c|c|c|c|}
\hline & Sum of Squares & Df & Mean Square & F & Sig. \\
\hline Between Groups & 14.687 & 5 & 2.937 & 19.136 & .000 \\
\hline Within Groups & 50.809 & 331 & .154 & & \\
\hline Total & 65.496 & 336 & & & \\
\hline
\end{tabular}

Results showed that $[\mathrm{F}(5,331)=19.136$, between the modal choice of the commuter $\mathrm{p}=0.000]$ a significant relationship exists versus his or her gender.

Table 3

Cross Tab (Modal Choice versus Age Group)

\begin{tabular}{|c|c|c|c|c|c|c|}
\hline \multicolumn{2}{|c|}{} & $\mathbf{1 8 - 2 5}$ years & $\mathbf{2 5 - 4 0}$ years & $\mathbf{4 0 - 6 0}$ years & >60 years & Total \\
\hline \multirow{4}{*}{$\begin{array}{c}\text { Current mode of } \\
\text { transport you use for } \\
\text { coming to ICBS }\end{array}$} & Bicycle & 11 & 2 & 0 & 1 & 14 \\
\cline { 2 - 8 } & Motorcycle & 119 & 17 & 2 & 0 & 138 \\
\cline { 2 - 8 } & Car & 35 & 10 & 1 & 1 & 47 \\
\cline { 2 - 8 }$y$ & PPV/SUV & 3 & 0 & 0 & 0 & 3 \\
\cline { 2 - 8 } & Public Bus & 100 & 9 & 0 & 0 & 109 \\
\cline { 2 - 8 } & Rickshaw & 24 & 2 & 0 & 0 & 26 \\
\hline
\end{tabular}

Results showed that motorcycle remain the favorite mode of travel of the youngster and young adults. $41 \%$ of total sample was using motorcycles as their mode of travel out of which $86 \%$ were young people of age group 18 25 years. $32 \%$ of total commuters were using public buses out of which $92 \%$ were the young commuters of age group between 18-25 years.

\section{Table 4}

ANOVA (Modal Choice versus Age Group)

\begin{tabular}{|c|c|c|c|c|c|}
\hline & Sum of Squares & Df & Mean Square & F & Sig. \\
\hline Between Groups & 2.642 & 5 & .528 & 2.948 & .013 \\
\hline Within Groups & 59.334 & 331 & .179 & & \\
\hline Total & 61.976 & 336 & & & \\
\hline
\end{tabular}

Results showed $[\mathrm{F}(5,331)=2.948, \mathrm{p}=$ significant important role in their modal $0.013]$ the age group of commuters plays choice.

\section{Table 5}

Cross Tab (Modal Choice versus Occupation)

\begin{tabular}{|c|c|c|c|c|c|}
\hline \multicolumn{2}{|c|}{} & Student & Teacher & Staff & Total \\
\hline \multirow{4}{*}{$\begin{array}{c}\text { Current mode of } \\
\text { transport you use for } \\
\text { coming to ICBS }\end{array}$} & Bicycle & 9 & 3 & 2 & 14 \\
\cline { 2 - 6 } & Motorcycle & 122 & 8 & 8 & 138 \\
\cline { 2 - 6 } & Car & 35 & 10 & 2 & 47 \\
\cline { 2 - 6 } & MPV/SUV & 3 & 0 & 0 & 3 \\
\cline { 2 - 6 } & Public Bus & 101 & 5 & 3 & 2 \\
\hline \multicolumn{2}{|c|}{ Tickshaw } & 23 & 1 & 27 & 337 \\
\hline \multicolumn{2}{|c|}{ Total } & 293 & 27 & 17 & 26 \\
\hline
\end{tabular}


It can be seen that motorcycles and public buses are the favorite travel modes of students with preference rates of $42 \%$ and $34 \%$ of the total students in the sample.
$37 \%$ teachers prefer the use of private cars for their daily college commute. $47 \%$ of the staff uses motorcycle as their mode of travel.

Table 6

ANOVA (Modal Choice versus Occupation)

\begin{tabular}{|c|c|c|c|c|c|}
\hline & Sum of Squares & Df & Mean Square & F & Sig. \\
\hline Between Groups & 2.874 & 5 & .575 & 2.347 & .041 \\
\hline Within Groups & 81.084 & 331 & .245 & & \\
\hline Total & 83.958 & 336 & & & \\
\hline
\end{tabular}

Result of ANOVA showed $[\mathrm{F}(5,331)=$ occupation of commuter on his or her modal $2.347, \mathrm{p}=0.041]$ a significant effect of the choice.

Table 7

Cross Tab (Modal Choice versus Monthly Income)

\begin{tabular}{|c|c|c|c|c|c|c|c|}
\hline \multicolumn{2}{|c|}{} & Unemployed & $\begin{array}{c}\mathbf{1 0 - 2 0 , 0 0 0} \\
\text { PKR }\end{array}$ & $\begin{array}{c}\mathbf{2 0 - 4 0 , 0 0 0} \\
\text { PKR }\end{array}$ & $\begin{array}{c}\mathbf{4 0 - 6 0 , 0 0 0} \\
\text { PKR }\end{array}$ & $\begin{array}{c}>\mathbf{6 0 , 0 0 0} \\
\text { PKR }\end{array}$ & Total \\
\hline \multirow{4}{*}{$\begin{array}{c}\text { Current mode } \\
\text { of transport } \\
\begin{array}{c}\text { you use for } \\
\text { coming to } \\
\text { ICBS }\end{array}\end{array}$} & Bicycle & 7 & 2 & 2 & 3 & 0 & 14 \\
\cline { 2 - 8 } & Motorcycle & 109 & 10 & 10 & 9 & 0 & 138 \\
\cline { 2 - 8 } & MPV/SUV & 28 & 5 & 5 & 8 & 1 & 47 \\
\cline { 2 - 8 } & Public Bus & 92 & 4 & 7 & 5 & 1 & 3 \\
\cline { 2 - 8 } & Rickshaw & 21 & 2 & 3 & 0 & 0 & 26 \\
\hline \multicolumn{2}{|c|}{} & 258 & 23 & 28 & 26 & 2 & 337 \\
\hline
\end{tabular}

Results indicated that as the income group of commuters increases their preference to the use motorcycles decreases. However, motorcycles and public buses remains the favorite travel mode for the students (unemployed) with preference rates of $42 \%$ and $36 \%$ respectively.

Table 8

ANOVA (Modal Choice versus Monthly Income)

\begin{tabular}{|c|c|c|c|c|c|}
\hline & Sum of Squares & Df & Mean Square & F & Sig. \\
\hline Between Groups & 21.523 & 5 & 4.305 & 4.770 & .000 \\
\hline Within Groups & 298.690 & 331 & .902 & & \\
\hline Total & 320.214 & 336 & & & \\
\hline
\end{tabular}

Results of ANOVA test $[\mathrm{F}(5,331)=4.770$, $\mathrm{p}=0.000]$ show that there exists statistical significant effect of the monthly income of commuters on their modal choice. 


\section{Table 9}

Cross Tab (Modal Choice versus Family Size)

\begin{tabular}{|c|c|c|c|c|c|c|}
\hline \multicolumn{2}{|c|}{} & $\mathbf{2}$ & $\mathbf{2 - 5}$ & $\mathbf{5 - 1 0}$ & above 10 & \\
\hline \multirow{4}{*}{$\begin{array}{c}\text { Current mode of } \\
\text { transport you use for } \begin{array}{c}\text { coming } \\
\text { coming to ICBS }\end{array}\end{array}$} & Bicycle & 2 & 4 & 5 & 3 & 14 \\
\cline { 2 - 8 } & Motorcycle & 8 & 79 & 45 & 6 & 138 \\
\cline { 2 - 8 } & Car & 3 & 29 & 14 & 1 & 47 \\
\cline { 2 - 8 } & MPV/SUV & 1 & 0 & 2 & 0 & 3 \\
\cline { 2 - 8 } & Public Bus & 5 & 52 & 47 & 5 & 109 \\
\cline { 2 - 8 } & Rickshaw & 3 & 8 & 14 & 1 & 26 \\
\hline
\end{tabular}

Results showed that the commuters with family size of 2-5 prefer the use of motorcycles (46\%), followed by public bus
(30\%) and cars (17\%). Result show similar trend for all the commuters with different family size groups.

Table 10

ANOVA (Modal Choice versus Family Size)

\begin{tabular}{|c|c|c|c|c|c|}
\hline & Sum of Squares & Df & Mean Square & F & Sig. \\
\hline Between Groups & 2.726 & 5 & .545 & 1.168 & .325 \\
\hline Within Groups & 154.579 & 331 & .467 & & \\
\hline Total & 157.306 & 336 & & & \\
\hline
\end{tabular}

Result shows $[\mathrm{F}(5,331)=1.168, \mathrm{p}=0.325] \quad$ This shows a non-significant effect where Fisher's $F$ value is almost equal to 1 of family size on the modal choice of and significance $\mathrm{p}$ is also $>0.05$. commuters.

\section{Table 11}

Cross Tab (Modal Choice versus Daily Travel Distance)

\begin{tabular}{|c|c|c|c|c|c|c|}
\hline \multicolumn{2}{|c|}{} & $\mathbf{2 0} \mathbf{~ K m}$ & $\mathbf{2 0 - 4 0 ~ K m}$ & $\mathbf{4 0 - 6 0 ~ K m ~}$ & $>\mathbf{6 0} \mathbf{~ K m}$ & Total \\
\hline \multirow{4}{*}{$\begin{array}{c}\text { Current mode } \\
\text { of transport you } \\
\text { use for coming to } \\
\text { ICBS }\end{array}$} & Bicycle & 6 & 3 & 3 & 2 & 14 \\
\cline { 2 - 8 } & Motorcycle & 86 & 37 & 10 & 5 & 138 \\
\cline { 2 - 8 } & Car & 29 & 10 & 5 & 3 & 47 \\
\cline { 2 - 8 } & MPV/SUV & 0 & 0 & 1 & 2 & 3 \\
\cline { 2 - 8 } & Public Bus & 38 & 28 & 31 & 12 & 109 \\
\cline { 2 - 8 } & Rickshaw & 20 & 1 & 54 & 25 & 337 \\
\hline \multicolumn{2}{|c|}{ Total } & 179 & 79 & & & \\
\hline
\end{tabular}

Results exhibited that as the travel distance of the commuter from the college increases their preference to use motorcycle as mode of travel decreases and the preference to use public bus as a mode increases. For example for sample group with less than $20 \mathrm{~km}$ travel distance $48 \%$ commuters use motorcycles followed by $21 \%$ who used public bus. As this travel distance goes for more than $60 \mathrm{~km}$ only $20 \%$ of sample group used motorcycle followed by $48 \%$ who used public bus. Trend to use private car for the travel remained similar throughout the groups. 
Table 12

ANOVA (Modal Choice versus Daily Travel Distance)

\begin{tabular}{|c|c|c|c|c|c|}
\hline & Sum of Squares & Df & Mean Square & F & Sig. \\
\hline Between Groups & 40.362 & 5 & 8.072 & 9.683 & .000 \\
\hline Within Groups & 275.947 & 331 & .834 & & \\
\hline Total & 316.309 & 336 & & & \\
\hline
\end{tabular}

Result $[F(5,331)=9.683, \mathrm{p}=0.000]$ where $\mathrm{F}>1$ and $\mathrm{p}<0.05$ exhibited that there exists a statistical significant relationship between the daily travel distance and the modal choice.

\section{Table 13}

Cross Tab (Modal Choice versus Driving License)

\begin{tabular}{|c|c|c|c|c|}
\hline & & No & Yes & Total \\
\hline \multirow{6}{*}{$\begin{array}{l}\text { Current mode of } \\
\text { transport you use for } \\
\text { coming to ICBS }\end{array}$} & Bicycle & 9 & 5 & 14 \\
\hline & Motorcycle & 74 & 64 & 138 \\
\hline & Car & 13 & 34 & 47 \\
\hline & MPV/SUV & 2 & 1 & 3 \\
\hline & Public Bus & 93 & 16 & 109 \\
\hline & Rickshaw & 24 & 2 & 26 \\
\hline \multicolumn{2}{|c|}{ Total } & 215 & 122 & 337 \\
\hline
\end{tabular}

Results showed that majority of commuters who do not have a driving license prefer to use public bus (43\%) for their daily travel to the college followed by motorcycle (34\%) and private cars $(6 \%)$ whereas those with driving license prefer to use their motorcycles (52\%) followed by private cars (28\%) and public bus (13\%). Commuters not having a driving license were 6 times more likely to use the public bus instead of their private vehicle.

Table 14

ANOVA (Modal Choice versus Driving License)

\begin{tabular}{|c|c|c|c|c|c|}
\hline & Sum of Squares & Df & Mean Square & F & Sig. \\
\hline Between Groups & 14.732 & 5 & 2.946 & 15.456 & .000 \\
\hline Within Groups & 63.102 & 331 & .191 & & \\
\hline Total & 77.834 & 336 & & & \\
\hline
\end{tabular}

Result $[\mathrm{F}(5,331)=15.45, \mathrm{p}=0.000]$ indicates that presence of driving license plays a significant role in the modal choice of the commuter.

\section{Discussions and Recommendations}

Discussions on the results obtained in this study and their corresponding recommendations are presented in this section. Results showed that majority of male commuters of an educational institute prefer the use of motorcycles while females are more inclined towards the use of public transport. Majority of young adults prefer to use motorcycles over public transport because of its convenience and accessibility. Motorcycle also remains the favourite modal choice of students while teachers prefer to use their private cars. Results indicate that 
economy remains the most determining factor in the modal choice of commuters. A $70 \mathrm{cc}$ single cylinder motorcycle provides an average mileage of more than 50 kilometres per litre in the city which makes it the first choice of students and staff members of an educational institute in Lahore. Results showed that family size of commuters did not have any significant effect on their modal choice. Results showed that as the travel distance of the destination from commuter's origin increases its preference to use public transport over the private transport also increases. This establishes a direct relationship between the travel distance and the usage of public transport. More than half of the commuters surveyed in this study did not have a driving license this is a serious point of concern for the traffic enforcement forces. Summary of the conclusions and recommendations are presented below:

a. Gender, age group, occupation, monthly income, daily travel distance and presence of driving license are the demographic and socio economic factors which significantly affect the modal choice of the commuter. Transport planners and practitioners must take into account these factors when planning the transport infrastructure system and modelling the travel demand of the road users;

b. Economy is the most important factor affecting the modal choice of commuters for their daily commute in an educational institution in Lahore;

c. Majority of commuters prefer the use of motorcycles over public buses because of the ease of access and punctuality which is lacking a great deal in the current public transport system of the city;

d. By improving the comfort level of public buses (condition of seats, interior aesthetics and quality) and punctuality of buses (timely arrival and depart schedules) commuters could be encouraged to use the public bus in place of their own vehicles thereby reducing the congestion on the roads;

e. Almost $64 \%$ people surveyed in this study did not have a driving license. This should be a matter of great concern and should be taken seriously by the traffic enforcement agencies. 


\section{References}

Hussain, A. 2016. Suzuki plans to stop the production of Cultus. Available from Internet: <http://www. pakistantoday.com.pk/2016/02/18/suzuki-plans-tostop-production-of-cultus.html $>$.

Hyder, A.; Ghaffar, A. 2006. Health and road transport in Pakistan, Public Health Journal 120(2): 132-141.

Imran, M. 2009. Public Transport in Pakistan: A critical overview, Journal of Public Transportation 12(2): 53-77.

Iversen, H.; Rundmo, T. 2004. Attitudes towards traffic safety, driving behaviour and accident involvement among the Norwegian public, Ergonomics 47(5): 555-572.

Jacobs, G.; Aeron-Thomas, A.; Astrop, A. 2000. Estimating global road fatalities. Crowthorne, UK, Transport Research Laboratory TRL Report. Available from Internet: <http://citeseerx.ist.psu. edu/viewdoc/download?doi=10.1.1.174.5207\&rep

$=$ rep $1 \&$ type $=$ pdf $>$.

Jaensirisak, S.; Klungboonkrong, P. 2009. Why Bus Rapid Transit (BRT) is interested by Transport Planners and Travellers in Thailand. In Proceedings of the Eastern Asia Society for Transportation Studies 7: 266-274.

JICA. 2012. The Project for Lahore Urban Transport Master Plan (LUTMP) in the Islamic Republic of Pakistan - Final Report. Japan International Cooperation Agency JICA. ALMEC Corporation Oriental Consultant Co. Ltd. Available from Internet: <open jicareport.jica.go.jp/pdf/12068110_01.pdf $>$.

Robert, D. 2011. An Ex Post Evaluation of the Ridership Impacts of the Viva Bus Transit System. MSc thesis, University of Toronto, Toronto, Canada. Available from Internet: <https://tspace.library.utoronto.ca/ bitstream/1807/30596/1/Forsey_Robert_D_201111 MASc_thesis.pdf $>$. 